\title{
ADAPTIVE DESIGN: WATER CURTAINS FOR WAYOUT FINDING IN HUB SPACES
}

\author{
F.A. PONZIANI ${ }^{1,2}$, A. TINABURRI ${ }^{1,2}, \& \mathrm{~V}$ RICCI $^{1}$ \\ ${ }^{1}$ Central Direction for prevention and technical safety - Department of firefighters, \\ of the public rescue and civil defence - Ministry of the Interior - Italy. \\ ${ }^{2}$ University of Rome Tor Vergata - Italy.
}

\begin{abstract}
The aim of this study is to explore some features of a complex system arising from the interactions of a fire stream in a hub space layout, with fire protection through water curtains issued by edge nozzles activated by smoke detectors. The hub layout represents the landside part of an airport terminal, made of clusters of semi-enclosed isles open to the inter-connected enclosed spaces that form a series of longitudinal paths with services and utilities. Once a fire source emits matter (smoke) and energy (enthalpy) out of one of the isle, in the absence of any fire protection barrier, the stream wanders following its buoyancy and the boundary conditions filling the available spaces inside the hub, making the occupants' conditions untenable. The design of water curtains that are activated in response to the fire onset may help to limit the dangerous spread of the fire stream and to support in the unfolding of protected paths for egress. While the activation of the water curtains in the proximity of the fire source once a threshold value is reached is the classical approach, a different design strategy is here investigated with CFD modelling based on a sequence of adaptive responses of the hub layout to the fire stream.

Keywords: adaptation, CFD, complex systems, edge nozzle, fire, FSE, water curtain.
\end{abstract}

\section{INTRODUCTION: FIRE AND CROWD ECOSYSTEMS}

This study is part of the research programme meant to explore Crowd and Fire Dynamics in their essence of Complex Systems [1]. In these kind of systems, the relationships between parts give meaning to the entire system, thus showing an Ecosystem. This is the case for a fire developing in an environment, where the interactions between fire and environment are responsible for the dynamic that will emerge, and when people get involved adding more complexity to the system, the interactions will include people behaviour that will bring about another kind of dynamic of evolution. While fire and crowd dynamics deserve understanding and studying on their own, so that each one of those two complex systems may reveal their nature independently - that matters anyway when there is no coupling between fire and crowd or when a design of a space layout is a task that requires knowledge of fire dynamics principles or of crowd dynamics principles alone - one more added value is understanding and studying of fire and crowd dynamics together - that matters when the coupling of fire and crowd streams is a major topic in design and management of the space layout [2].

Be fire and people independent, or not, this study presents an innovative viewpoint: fire and people form an ecosystem where the typical characteristics of fire dynamics (i.e. smoke streams) and of crowd dynamics (i.e. people streams) interact with the environment and evolve with emerging properties depending on the interactions. The shift of the focus is from the single parts to the interactions [3]; for smoke management: stopping and channelling of smoke stream with interactive means such as vents and curtains that activate with a sequence linked to the smoke advancement; for egress management: way-out finding activities linked to paths pre-defined or unfolding depending on the advancement of the dangerous menace. Interactions are one typical aspect of Complex Systems from which emergent behaviour may appear in several forms, unpredictable yet not random [4]: the understanding of what kind of 
emerging patterns arise is one main problem of this research project, where the fire stream may evolve with patterns in different ways depending just on the interactions between the system components, such as smoke advancing front and active protection devices, and environment layout.

This study deals with a hub design with water curtains that activate in sequence to help reduce the effects of smoke spreading from a fire source. The hub layout represents the landside part of an airport terminal, made of clusters of semi-enclosed isles open to the inter-connected enclosed spaces that form a series of longitudinal paths with services and utilities.

Once a fire source emits its stream of matter (smoke) and energy (enthalpy) out of one of the isle, in the absence of any fire protection barrier, the stream wanders following its buoyancy and the boundary conditions filling the available spaces inside the hub, sooner or later making the occupants' conditions untenable.

Water curtains that activate in response to the fire onset may help to limit the dangerous consequences of the spread of the fire stream - at least for some time useful to start control or suppression of the fire source or to start egress of occupants - and to support in the unfolding of protected paths for way-out - thus making adaptation of the system a focus for egress - especially when supported by some means for limiting fire growth at the source.

Instead of activating the water curtains only in the proximity of the fire source once a threshold value is reached, as in a standard design, the activation of the water curtains is based on a sequence of variable responses of the hub layout to the fire stream. At the advancement of the fire/smoke stream, while the water curtains activating near the fire source may help in controlling and reducing the spread, other water curtains along the hub are activated if critical targets - not necessarily located near the edge nozzles - reach a threshold value due to the exposure to the stream advancement. Such exposure, that may be of temperature, heat flux, visibility at the targets, then triggers the dynamical response of the fire protection system, thus letting the system adapt to the fire stream evolution. CFD modelling allows to study the interactions of the fire/smoke stream with the hub layout and the response of the water curtains and the protected paths unfolding for way-out. In this way, the network made of active protection devices (smoke detectors and water curtains linked for activation) delivers a connection through the system that offers, by means of decentralized nodes (the devices themselves), the possibility for the system to adapt to the evolution dynamics occurring (i.e. the fire/smoke current) and deploy a resilient response (i.e. avoiding a full fire/smoke involvement in - at least some part of - the environment), thus enabling the formation of protected spaces (i.e. paths for way-out for people inside).

\section{FIRE ENGINEERING DESIGN: SPACE LAYOUT AND CFD}

The space layout of the hub considers an airport that is composed of one base floor level and a single height ceiling, representing the landside space of the terminal, with an overall striplike shape in plan. On the left side, two partially open square spaces connect to a central concourse, while on the slightly narrower right side a couple of linear walls with turning end corners mark the line. There are four doors to the outside, two in the front part of the concourse and one for each end side, while there are four passageways for each square space isle that partially open to the concourse and two wide passageways that merge the linear walls and the concourse. The total length of the airport space is $60 \mathrm{~m}, 32 \mathrm{~m}$ on the left and $28 \mathrm{~m}$ on the right, the total width is $12 \mathrm{~m}$ on the left and $8 \mathrm{~m}$ on the right, the total height is $4 \mathrm{~m}$.

The two square-sided isles on the left have a ceiling on top at the height of $3 \mathrm{~m}$, while there is always an open space on top of the floor bounded by the linear walls up to the ceiling at the height of $4 \mathrm{~m}$ that is running all over the airport. The dimension of the doors, passageways 
and exits - essentially the width - can be varied based on the code followed for the design, where several dimensions have been considered in this study, with one group of them here reported in the remainder.

The following Figs 1 and 2 show a plan view and a rendering of the airport.

The following Table 1 summarizes the zones into which the hub space is divided for functional identification.

Once defined the hub layout, a fire engineering design by means of a CFD study is required to examine the impact of the layout on the development of a fire starting from a spot in one stand. Due to the fire safety provisions requiring few to no combustible materials in such

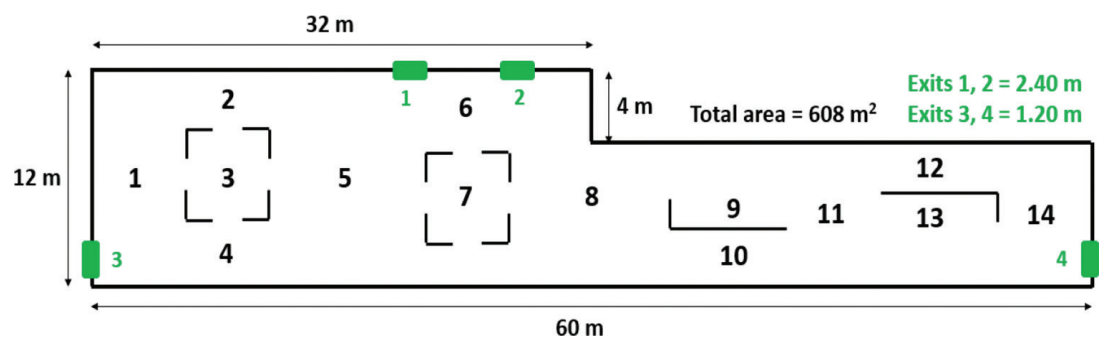

Figure 1: Plan view of the Hub.

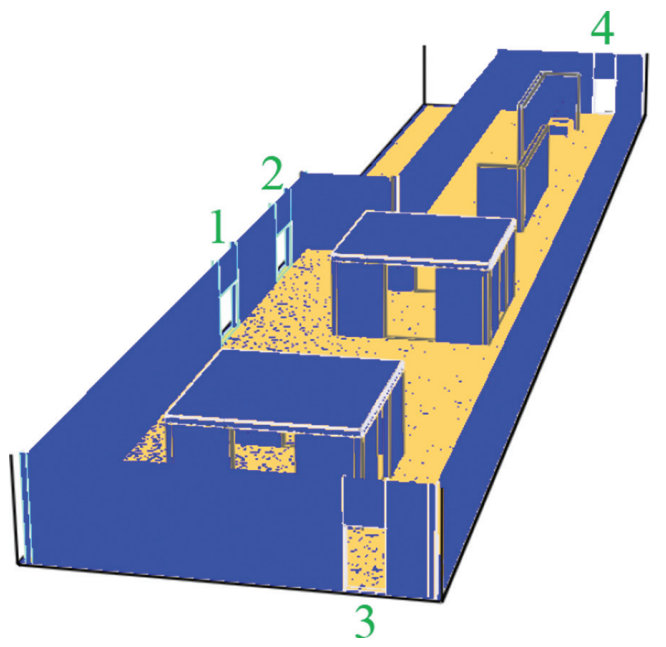

Figure 2: The Hub space.

Table 1: Functional identification of zones in the Airport hub.

\begin{tabular}{llll}
\hline Zone & Identification & Function & $\begin{array}{l}\text { Ceiling } \\
\text { height }\end{array}$ \\
\hline $1-5-8-11-14$ & Central concourse & Capacity for gathering people/smoke & $3.80 \mathrm{~m}$ \\
$2-4-6-10-12$ & Sideway concourse & Capacity for moving people/smoke & $3.80 \mathrm{~m}$ \\
$3-7$ & Square-sided isles & Space for stand & $2.80 \mathrm{~m}$ \\
$9-13$ & Linear walls & Space for stand & $3.80 \mathrm{~m}$ \\
\hline
\end{tabular}


critical parts in the concourse needed to guide the occupants along way-out finding, the only places where a fire could be started - accidentally or voluntarily - are in the stands, albeit with a minor firepower allowed (i.e. by means of proper items with low heat/smoke production rates) in order to avoid a fast spread from the ignited source.

The CFD package Fire Dynamic Simulator (FDS) and its companion visualizer Smokeview (versions 6) are used in LES mode for modelling turbulence [5]. One domain with single mesh discretization is set-up for modelling the hub space; inert materials are assigned to describe the boundaries (i.e. floor, walls, ceilings) and the fire spot is modelled as a burner emitting an assigned firepower, where the reaction type is for plastic material combustion. Two scenarios are considered for the position of the fire source: in a corner in the central isle in the left part of the airport (F1) and in the corner of the right wall in the right end side of the airport (F2). This choice makes it possible to examine the spreading of the smoke stream moving along the hub from two opposite sides.

The CFD domain reproduces the hub layout shown in Fig. 2, with the following Table 2 summarizing the main input properties.

Once defined the model, CFD is used to study the interactions arising between the fire and the environment: the evolution of the dynamics modelled will be observed in such a way to start with a base case without active protection systems aimed at controlling the fire spread, followed by the introduction of active protection measures inserted to bias the dynamics of the fire. The active protection system considered in this study combines water curtains, placed in critical parts of the layout, with smoke detectors used for their activation.

Depending on the advancement of the fire/smoke stream, the smoke detectors will trigger the water curtains according to the design strategy, either following (adaptive design) or anticipating (generative design) the effects of the fire. The design key parameters to be assessed during the fire evolution may be the visibility loss, the gas temperature rise, the flow field vorticity induced by the water curtains interacting with the smoke. This methodology approach is thought and applied to try to let the system organize by itself with action-reaction behaviours biased on the interactions appearing during the very evolution dynamics occurring (i.e. different evolution dynamics lead to different interactions, hence to different action-reaction behaviours, hence to different organization of the system).

\section{DESIGN BASIS}

The first design step is modelling the fire evolution in the hub without water curtains operating. Among all the possible scenarios, two key alternative events are chosen: a fire starting in

Table 2: Input properties for CFD modelling.

\begin{tabular}{ll}
\hline Property & Setup \\
\hline Domain & Single mesh-grid \\
Mesh-grid & Cubic cells \\
Turbulence modelling & Large Eddy Simulation (LES) with Sub Grid Scale (SGS) \\
SGS turbulence & Deardorff \\
Fire source & Burner \\
Firepower & Constant release \\
Reaction type & Plastic combustion \\
Soot emission & Constant yield \\
\hline
\end{tabular}


a square-sided isle on the left part of the hub (zone 7, scenario F1) and a fire starting at a guide wall on the right part of the hub (zone 13, scenario F2).

The following Fig. 3 shows the fire source locations, that are chosen since they host stands where combustible installations and appliances may temporarily be present. The presence/ absence of a ceiling above the fire source lower than that of the hub is also taken into account: the stand in the isle has its own incombustible ceiling (at a lower height of $3 \mathrm{~m}$ ), while the guide wall has a height limited to $3 \mathrm{~m}$ and the space above it is open up to the hub roof level (being $4 \mathrm{~m}$ throughout the terminal space). So, two differing kind of fire/smoke stream originate from a fire source of the same power and type.

The following Tables 3 and 4 summarize the fire and environmental parameters adopted for CFD modelling.

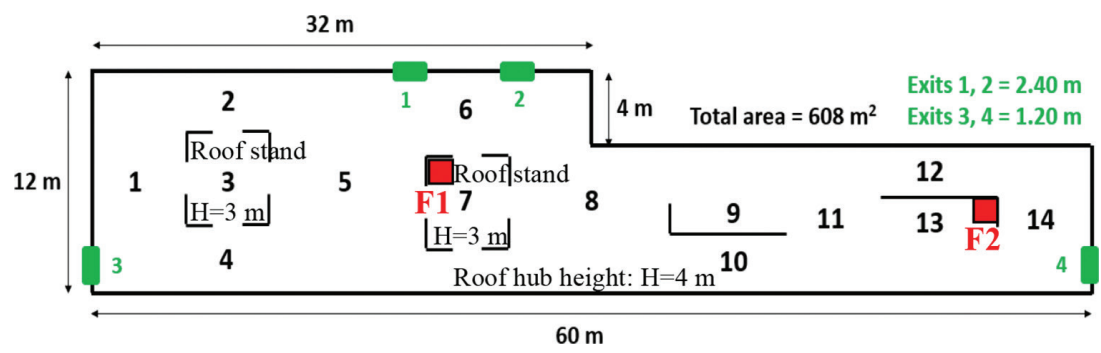

Figure 3: Alternative fire scenarios.

Table 3: Fire parameters for CFD modelling.

\begin{tabular}{ll}
\hline Parameter & Value \\
\hline Domain & 60 m length $12 \mathrm{~m}$ width 4 m height \\
Mesh-grid & $\begin{array}{l}\text { Cubic cells. } \\
\text { Reference size: } 20 \mathrm{~cm} . \text { Sensitivity analysis: minimum size } 10 \mathrm{~cm} \\
\text { Corner in the left central square isle or in the right guide wall }\end{array}$ \\
Fire source & Steady-state $100 \mathrm{~kW}$ \\
Firepower & Polyurethane \\
Combustion reaction & 0.10 \\
Soot yield & Stand in isle or wall \\
Spot with fire & Lower own ceiling for isle or higher hub ceiling for wall stands \\
Above top of fire & At ceiling when active \\
Smoke detectors & At ceiling when active \\
Water curtains &
\end{tabular}

Table 4: Environmental parameters for CFD modelling.

\begin{tabular}{ll}
\hline Parameter & Value \\
\hline Temperature & $288 \mathrm{~K}$ \\
Density & $1.22 \mathrm{~kg} \mathrm{~m}^{-3}$ \\
Specific heat at constant pressure & $1.0 \mathrm{~kJ} \mathrm{~kg}^{-1} \mathrm{~K}^{-1}$ \\
Gravity field & $9.81 \mathrm{~m} \mathrm{~s}^{-2}$ \\
\hline
\end{tabular}


The second design step assesses the effectiveness of the water curtains for the selected fire scenarios. Each curtain is formed by a series of nozzles placed aside at a same properly chosen height, thus forming a horizontal line, with an opening slot issuing a downward water flow forming a fan shaped curtain opening downward too. The set of sided single fan shaped curtains forms the overall water curtain as a whole. While not explicitly considered because not necessary for this study, it is assumed that a water supply is available to guarantee the required flow rate at the open nozzles (differing from sprinkler heads that are closed by a thermo-sensible element). Experimental testing is almost always necessary to verify and confirm the hydraulic design assumptions; some parameters adopted in this study to model the water flow come from a previous work carried out by the authors [6].

The water curtains are placed in some critical parts of the hub, i.e. in the central concourse and in the stand zones; their activation strategy is one major topic dealt with in this study. When there is no automatic control of the activation, the water curtains discharge their flow at the starting of the hydraulic system that, at most, can be triggered by a manual command scheduled at the discovery of the fire onset: we refer to this strategy as to the standard design. When there is an automatic control of activation (i.e. by smoke detectors), the water discharge is initiated after a logic sequence is performed: this means that the hydraulic system operation is linked to the control strategy.

When the activation of the water curtains by the controllers follows the event (i.e. the smoke advancement from the fire source), we refer to this as to the adaptive design. When the activation of the water curtains by the controller anticipates the event, we refer to this as to the generative design.

It is worth noting that the connection between the hydraulic system and the mastering controllers need not be necessarily localized near the water curtains, as it would be in the case of a sprinkler system, but it can be designed choosing the controller devices position in the layout in such a way to delocalize, as it would be in the case of a pre-action sprinkler system. This allows the use of multiple control devices thus enhancing the possibility of early detection and counter-measure of the fire threat. In that way, it is possible to guide the active protection along the very fire dynamic that is evolving in the system, either in defence (adaptive) or in attack (generative). It could be noted that this approach resembles closely what is done in the process control field, where the adaptive strategy is known as feed-back control mode and the generative strategy is called feed-forward control mode [7].

The following Table 5 summarizes the water curtains hydraulic and control logic parameters adopted for CFD modelling.

The following Tables 6 and 7 summarize respectively the location of the water curtains and of the smoke detectors and the sequences of activation, defining the type of design.

The protection devices can be classified depending on their function into detectors and activable ones. A strategy matrix can thus be designed where the columns are the detectors (in our study smoke sensors $S_{j}$ ) and the rows are the activable devices (in our study water curtains $\mathrm{W}_{\mathrm{i}}$ ), whose elements are assigned a value 0 or 1 depending on their link. A logic code could then be developed combining two data sets: the first part identifies the fire scenario and the following the strategy matrix per row. This code defines the response of the whole system along its evolution dynamics [8], identifying the design strategy that might be implemented on a control panel. In that way the system self-organization is made evident, with the fire protection system autonomously able to respond to a fire/smoke event with the decentralized, and not centrally controlled, protection devices linked for activation. 
Table 5: Water curtains hydraulic and control logic parameters for CFD modelling.

\begin{tabular}{ll}
\hline Parameter & Value \\
\hline Nominal flow rate & $181 \mathrm{~min}^{-1}$ \\
Frontal screen opening angle & $120^{\circ}$ \\
Side screen opening angle & $6^{\circ}$ \\
Pressure at nozzle & $6 \mathrm{barg}$ \\
Initial velocity & $3.75 \mathrm{~m} \mathrm{~s}^{-1}$ \\
Mean droplet diameter & $200 \mu \mathrm{m}$ \\
Statistical droplet distribution & Rosin-Rammler-Lognormal (default FDS) \\
Injection rate & 5000 particles per second (default FDS) \\
Controllers of activation & Smoke detectors activated with the single parameter \\
& Heskestad model (default FDS) \\
\hline
\end{tabular}

Table 6: Active protection devices: water curtains and smoke detectors.

\begin{tabular}{lllll}
\hline Device & Identification & Location & Zone & $\begin{array}{l}\text { Height of } \\
\text { device }\end{array}$ \\
\hline Water curtains at concourse & W1 & Central concourse & 8 & $3.80 \mathrm{~m}$ \\
Water curtains at concourse & W4 & Central concourse & 11 & $2.80 \mathrm{~m}$ \\
Water curtains at stand isle & W2 & Square sided-isle & 3 & $2.80 \mathrm{~m}$ \\
Water curtains at stand isle & W3 & Square sided-isle & 7 & $2.80 \mathrm{~m}$ \\
Water curtains at stand isle & W4 & Linear wall & 9 & $2.80 \mathrm{~m}$ \\
Water curtains at stand isle & W4 & Linear wall & 13 & $2.80 \mathrm{~m}$ \\
Smoke detector at concourse & S5 & Central concourse & 5 & $3.60 \mathrm{~m}$ \\
Smoke detector at concourse & S1 & Central concourse & 8 & $3.60 \mathrm{~m}$ \\
Smoke detector at concourse & S4 & Central concourse & 11 & $3.60 \mathrm{~m}$ \\
Smoke detector at stand isle & S2 & Square sided-isle & 3 & $2.80 \mathrm{~m}$ \\
Smoke detector at stand isle & S3 & Square sided-isle & 7 & $2.80 \mathrm{~m}$ \\
\hline
\end{tabular}

Table 7: Active protection devices: water curtains and smoke detectors.

\begin{tabular}{|c|c|c|c|}
\hline Fire scenario & Smoke detection & $\begin{array}{l}\text { Water curtains } \\
\text { activation }\end{array}$ & Design type \\
\hline \multirow{4}{*}{$\begin{array}{l}\text { Stand in the isle } 7 \\
\text { (scenario F1) }\end{array}$} & S3 & W3 & \multirow[t]{4}{*}{ Adaptive } \\
\hline & $\mathrm{S} 1$ & W1 & \\
\hline & $\mathrm{S} 2$ & W2 & \\
\hline & $\mathrm{S} 4$ & W4 & \\
\hline \multirow{4}{*}{$\begin{array}{l}\text { Stand near the wall in zone } 13 \\
\text { (scenario F2) }\end{array}$} & $\mathrm{S} 4$ & W4 & \multirow[t]{4}{*}{ Generative } \\
\hline & $\mathrm{S} 4$ & W1 & \\
\hline & $\mathrm{S} 1$ & W3 & \\
\hline & S5 & W2 & \\
\hline
\end{tabular}


Table 8: Evolution response: system code strings

\begin{tabular}{lcccl}
\hline Fire scenario & $\mathrm{W}_{\mathrm{i}} \mathrm{S}_{\mathrm{j}}: 1^{\text {st }}$ row & $\mathrm{W}_{\mathrm{i}} \mathrm{S}_{\mathrm{j}}: 2^{\text {nd }}$ row & $\mathrm{W}_{\mathrm{i}} \mathrm{S}_{\mathrm{j}}: 3^{\text {rd }}$ row & $\mathrm{W}_{\mathrm{i}} \mathrm{S}_{\mathrm{j}}: 4^{\text {th }}$ row \\
(F1) 01 & 10000 & 01000 & 00100 & 00010 \\
System code string: 0110000010000010000010 (Adaptive design) & \\
(F2) 10 & 00010 & 00001 & 10000 & 00010 \\
System code string: 1000010000011000000010 (Generative design)
\end{tabular}

In our study two fire scenarios F1 and F2 are considered, with the assigned strings 01 and 10 , with four water curtains and five smoke detectors. The preceding Table 8 shows the system code strings thus obtained.

\section{CFD: BASELINE DESIGN WITHOUT ACTIVE PROTECTION SYSTEMS}

The baseline design case is chosen with the fire evolving without any water curtains operating. Fire scenario F1 is the base case for the analysis of the effect of the adaptive strategy while fire scenario F2 is the base case for the generative strategy. Some selected results of the CFD simulations are shown in the following Figs 4 and 5.

The fire dynamics in the absence of active protection intervention is simulated with a $20 \mathrm{~cm}$ mesh grid for a time interval of $120 \mathrm{~s}$ (ignition at time 0), long enough to allow the comparison with the simulation where the water curtains are triggered by the detectors in response to the smoke advancement.

In fire safety engineering, when dealing with the early stage of a fire, the main threat for the occupants is represented by the smoke. Without any active protection system, in the layout studied the smoke spreads throughout the whole compartment mainly flowing at the

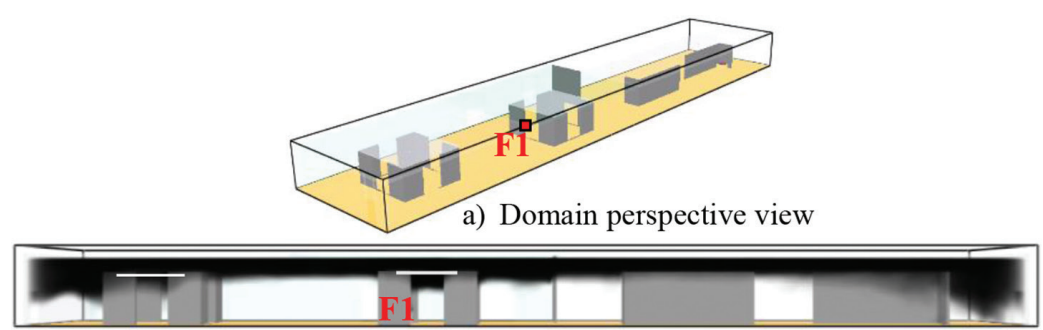

b) Smoke flow: longitudinal frontal view

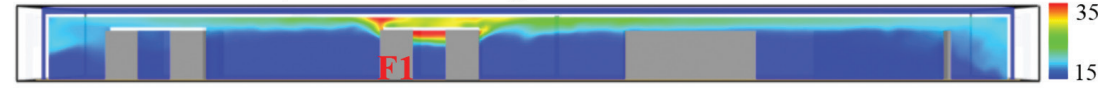

c) Gas temperature $\left({ }^{\circ} \mathrm{C}\right)$ : vertical section across the fire source

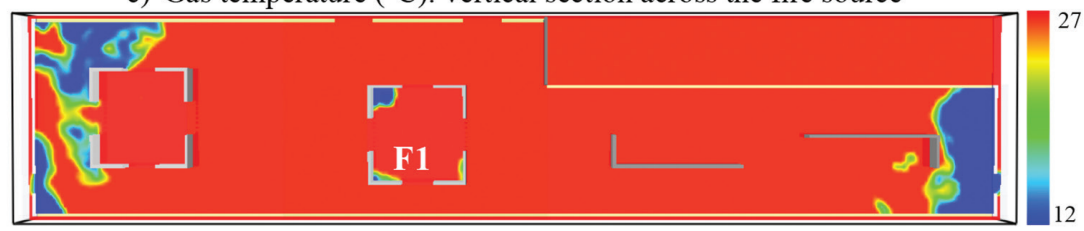

d) Visibility (m): horizontal section at $1.6 \mathrm{~m}$ height above the floor

Figure 4: Scenario F1 without water curtains operating - 120 s from ignition. 


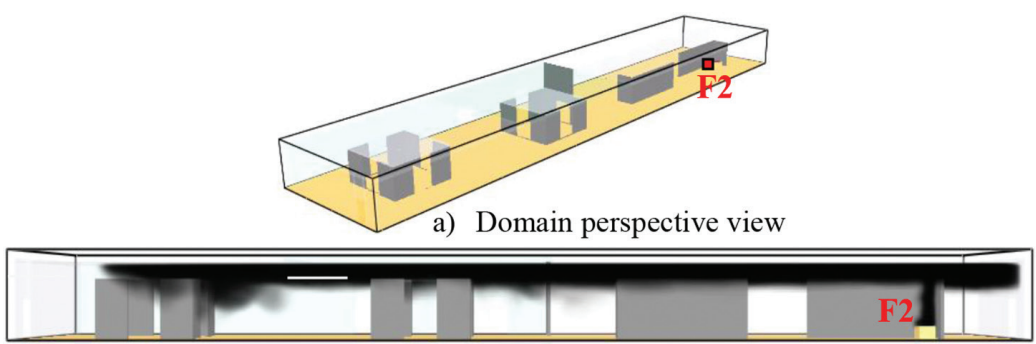

b) Smoke flow: longitudinal frontal view

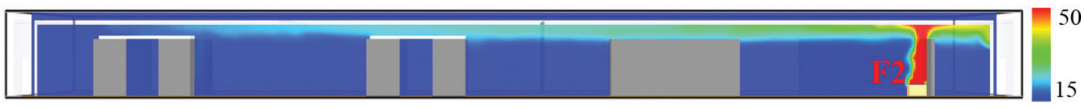

c) Gas temperature $\left({ }^{\circ} \mathrm{C}\right)$ : vertical section across the fire source

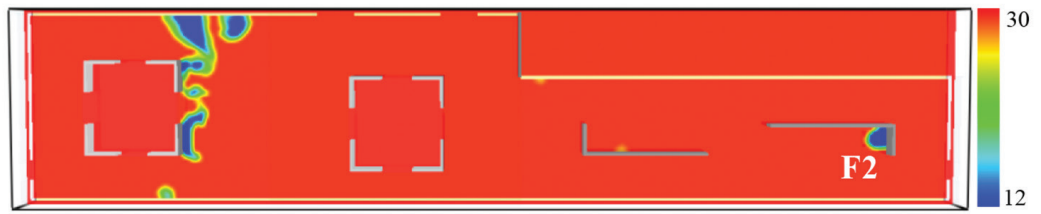

d) Visibility (m): horizontal section at $1.6 \mathrm{~m}$ height above the floor

Figure 5: Scenario F2 without water curtains operating - 120 s from ignition.

ceiling level and reaches the side boundaries in a time span in the order of a few minutes, even with a low intensity fire source. It is worth noting the increased vorticity appearing in correspondence of the interaction of the smoke layer with obstacles far away from the fire source and the shape of the smoke front while advancing freely along the ceiling.

\section{CFD: ACTIVE PROTECTION ADAPTIVE DESIGN}

In the adaptive design the smoke detector activates its linked water curtains in a sequence that follows the smoke front advancement. The following Figs 6 and 7 show some selected CFD results and the domain for the $10 \mathrm{~cm}$ mesh with the smoke detectors and water curtains: the activated smoke detectors and the linked water curtains are shown respectively in red and blue colours. The smoke detector S3 is the first to trigger the water curtains W3 after $\sim 6 \mathrm{~s}$; $\mathrm{S} 1$ triggers $\mathrm{W} 1$ after $\sim 24 \mathrm{~s}$ ( $26 \mathrm{~s}$ for the coarsest grid). Water flow rendering is made visible only in the first two snapshots (Fig. 6 a and b) for the sake of clarity.

At $120 \mathrm{~s}$, when the simulation is stopped, there is no further smoke detector activation. The water curtains W3 favour the smoke accumulation inside the stand on fire (recall that there is no direct intervention on the fire source, which is assumed steady-state). The water curtain W1 obstacles the smoke propagation beyond it; the smoke outflowing from the stand on fire is therefore forced to direct mainly on the left side of the hub space.

Compared with the baseline case simulation, water curtains induce zones of high vorticity at the floor level. While the smoke is still propagating mainly along the ceiling, smoke destratification is observed around the stand on fire and in the space between the stand and the water curtain $\mathrm{W} 1$, impacting negatively on the visibility conditions in this zone. With the low intensity fire source assumed, the gas temperature rise at ceiling level is in the order of $10^{\circ} \mathrm{C}$, while in the baseline case is in the order of $20^{\circ} \mathrm{C}$. 
(a)

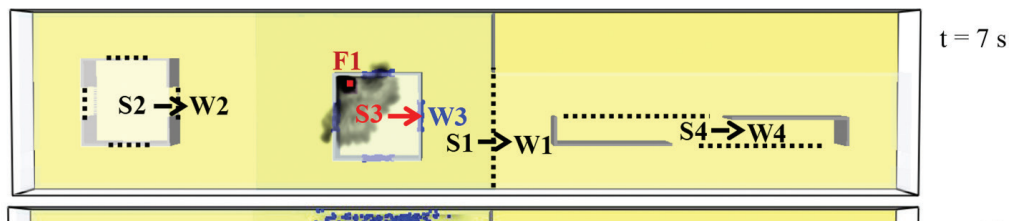

(b)

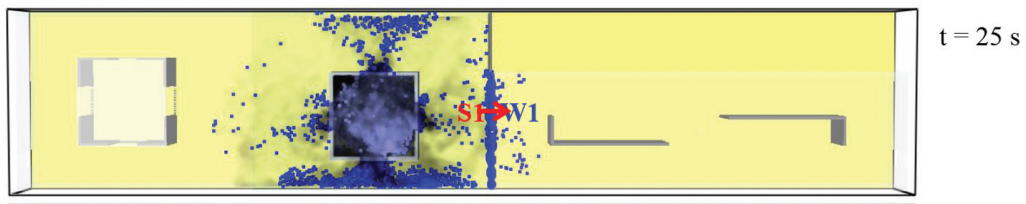

(c)

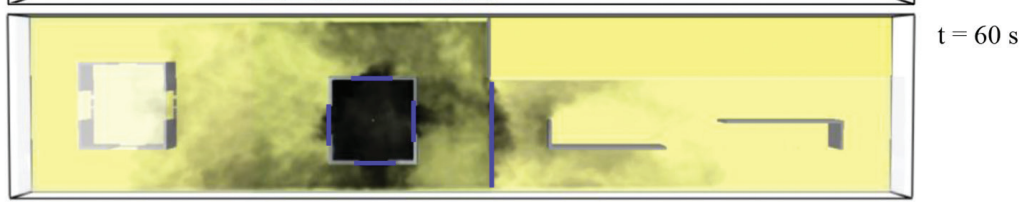

(d)

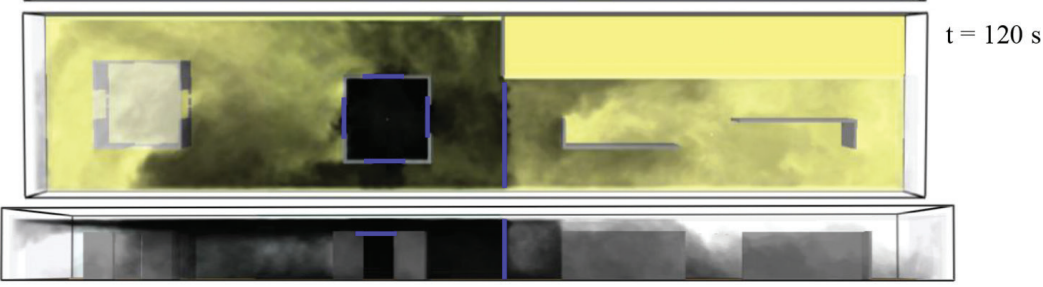

Figure 6: Scenario F1 with water curtains (Adaptive design) - Smoke flow sequence: top view at 7, 25, 60 and $120 \mathrm{~s}$ (with the hub ceiling clipped); longitudinal front view at $120 \mathrm{~s}$.

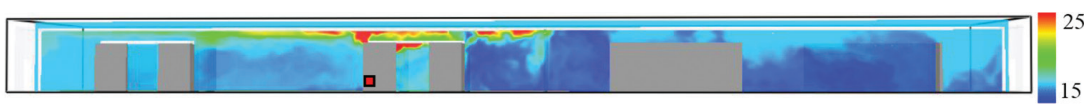

a) Gas temperature $\left({ }^{\circ} \mathrm{C}\right)$ : vertical section across the fire source

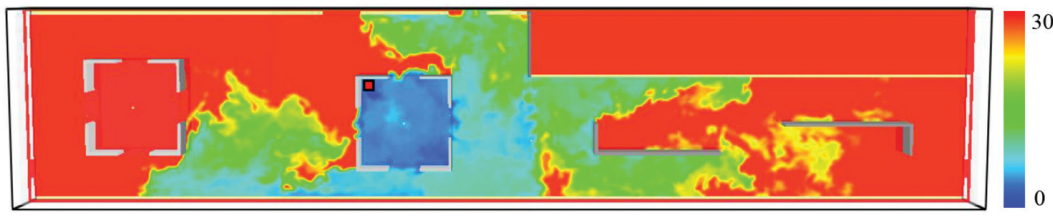

b) Visibility (m): horizontal section at $1.6 \mathrm{~m}$ height above the floor

Figure 7: Scenario F1 with water curtains (Adaptive design) - 120 s from ignition.

\section{CFD: ACTIVE PROTECTION GENERATIVE DESIGN}

In the generative design the smoke detector activates its linked water curtains in a sequence that anticipates the smoke front advancement. The following Figs 8 and 9 show some selected CFD results and the domain for the $10 \mathrm{~cm}$ mesh with the smoke detectors and water curtains: the activated smoke detectors and the linked water curtains are shown respectively in red and blue colours. The smoke detector S4 is the first to trigger the water curtains W4 and W1 after $\sim 17 \mathrm{~s}$ ( $\sim 22 \mathrm{~s}$ for the coarsest grid); S1 triggers W3 after $\sim 90 \mathrm{~s}$ ( $\sim 92 \mathrm{~s}$ for the coarsest grid). Water flow rendering is hidden for the sake of clarity. 


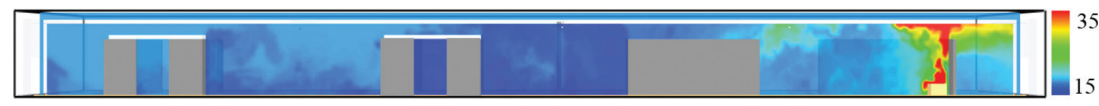

a) Gas temperature $\left({ }^{\circ} \mathrm{C}\right)$ : vertical section across the fire source

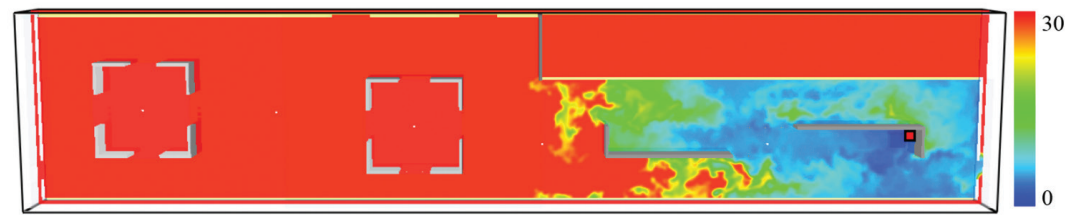

b) Visibility (m): horizontal section at $1.6 \mathrm{~m}$ height above the floor

Figure 8: Scenario F2 with water curtains (Generative design) - 120 s from ignition.

(a)

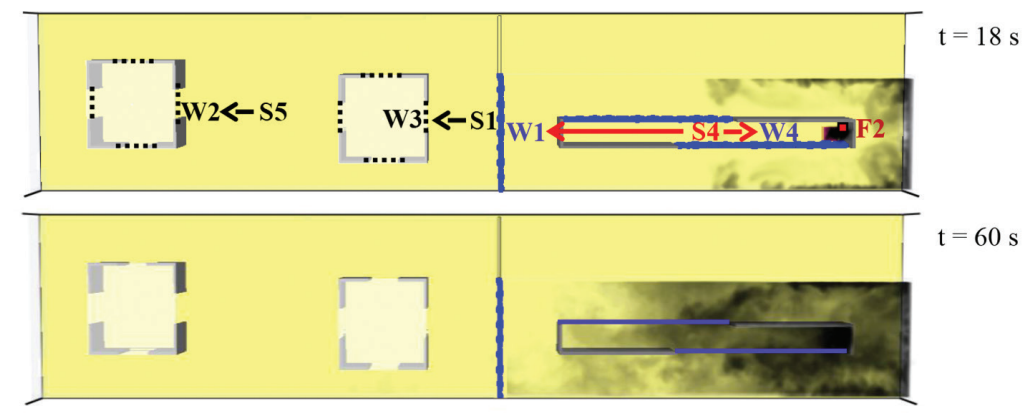

(c)

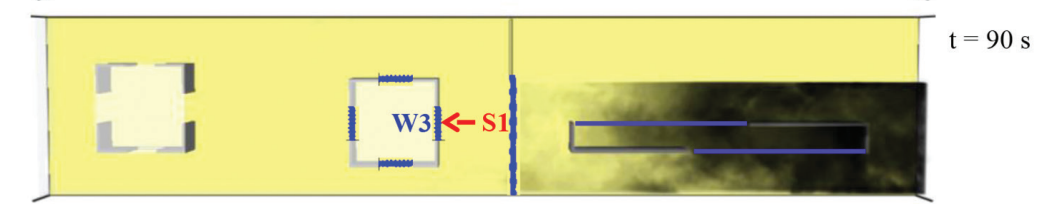

(d)
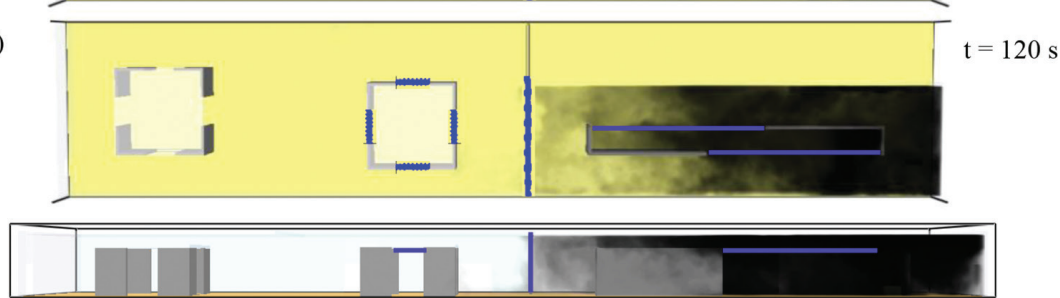

Figure 9: Scenario F2 with water curtains (Generative design) - Smoke flow sequence: top view at $18,60,90$ and $120 \mathrm{~s}$ (with the hub ceiling clipped); longitudinal front view at $120 \mathrm{~s}$.

At $120 \mathrm{~s}$, when the simulation is stopped, there is no further smoke detector activation. The water curtains W4 are deliberately placed at a lower level than the hub ceiling so that the smoke produced by the fire can overpass them in order to activate further protective devices (generative design strategy meant to anticipate the active protection response). Since W4 completely surround the fire source filling the gaps between the linear walls, smoke accumulation in zones 11 and 13 is still observed. The water curtain W1 is activated simultaneously with W4 well in advance of the smoke front arrival. The smoke outflowing from the stand on fire directs mainly on the right side of the hub space, reaching a critical state after $\sim 90 \mathrm{~s}$ when smoke detector S1 is activated. With a generative design, the nearest sensible target, i.e. the 
stand in the isle 7, is protected by the water curtain W3. Compared with the previous simulation, water curtains seem to induce less vorticity at the floor level. While the smoke is still propagating mainly along the ceiling, smoke destratification is observed around the stand on fire. The gas temperature rise at ceiling level is now in the order of $20^{\circ} \mathrm{C}$, while in the baseline case is in the order of $40{ }^{\circ} \mathrm{C}$.

\section{CONCLUSION: ECOSYSTEMS}

The fire and crowd ecosystems, alone or coupled, live on interactions that define their evolution dynamics. Critical events may appear, disappear, mutually interfere, depending on their nature and the constraints from the environment. One such example of ecosystem has been exploited in this study, where active protection systems with water curtains activated by smoke detectors have been designed to respond to the advancement of the smoke stream produced by the fire source (i.e. the fire stream), thus providing a support for enhancing way-out finding (i.e. the crowd stream) either following the events (adaptive design: following the smoke advancement) or anticipating them (generative design: anticipating the smoke advancement). While further refinement, easily added, is needed for direct application, requiring evaluation of the relative strengths of the fire stream and of the water curtains with higher values of the parameters (i.e. firepower, flow rate), together with experimental tests for parameters assessment, the design process depicted here shows an innovative viewpoint in fire research and engineering that takes into account the very nature of ecosystem of such complex systems as fire and crowd systems. Coupling CFD modelling and experimental campaigns of water curtains may lead to efficient and improved solutions, where outcomes (i.e. reduced smoke spreading, thermal screen) and drawbacks (i.e. smoke crossing and rolling vortex) of the water curtains are balanced and active protection is enhanced by means of proper design (i.e. denser water screens, curtains in series) and of further interacting devices (i.e. smoke curtains, smoke channelling and venting) [9-12]. Furthermore, by recognising the complexity of systems involving fire and crowd streams development may help to deepen the understanding of those complex systems and to approach the related fire safety engineering with innovative and practical solutions and design strategies.

\section{REFERENCES}

[1] Erdi, P., Complexity Explained, Springer: Berlin, 2008.

[2] Hurley, M.J. (ed), The SFPE Handbook of Fire Protection Engineering, 5th Edition, Springer-Verlag: Berlin and New York, 2016.

[3] Haken, H., Synergetics. Introduction and Advanced Topics, Springer: Berlin, 2004.

[4] Rzevski, G., Harnessing the power of self-organization. International Journal of Design \& Nature and Ecodynamics, 11(4), pp. 483-494, 2016. https://doi.org/10.2495/dne-v11-n4-483-494

[5] Mc Grattan, K., Hostikka, S., Floyd, J., Weinschenk, C. \& Overholt, K. (eds), Fire Dynamics Simulator v.6. Technical Reference Guide, NIST Special Publication 1018-1, 2015.

[6] Ponziani, F.A., Tinaburri, A. \& Ricci, V., Water curtains for fire protection: experimental tests and CFD modelling. International Journal of Safety and Security Engineering, 8(1), pp. 1-9, 2018. https://doi.org/10.2495/safe170091

[7] Shinskey, F.G., Process Control Systems, Mc Graw-Hill: New York, 1996. 
[8] Holland, J.P., Adaptation in Natural and Artificial Systems, MIT Press: Cambridge MA, 1992.

[9] Roytman, M.Ya., Principles of Fire Safety Standards for Building Construction, Amerind: USA, 1975.

[10] Centro Studi Esperienze CNVVF (ed.), Barriere Idriche, Rome, 1999 (in Italian).

[11] Choi, C.L., Radiation blockage effects by water curtain. International Journal on Engineering Performance-Based Fire Codes, 6(4), pp. 248-254, 2004.

[12] Cheung, W.Y., Radiation Blockage of Water Curtains, International Journal on Engineering Performance-Based Fire Codes, 1, pp. 7-13, 2009. 